\title{
Target, Suspect and Non-Target Screening of Silylated Derivatives of Polar Compounds Based on Single Ion Monitoring GC-MS
}

\author{
Bhekumuzi Prince Gumbi ${ }^{1}\left(\right.$, Brenda Moodley ${ }^{1}$, Grace Birungi ${ }^{2}$ and \\ Patrick Gathura Ndungu $3, *$ (D) \\ 1 School of Chemistry and Physics, University of KwaZulu-Natal, Durban 4000, South Africa; \\ GumbiB@ukzn.ac.za (B.P.G.); Moodleyb3@ukzn.ac.za (B.M.) \\ 2 Department of Chemistry, Mbarara University of Science and Technology, Mbarara 1410, Uganda; \\ gbirungi@must.ac.ug \\ 3 Department of Chemical Sciences, University of Johannesburg, Johannesburg 2028, South Africa \\ * Correspondence: pndungu@uj.ac.za
}

Received: 26 June 2019; Accepted: 11 September 2019; Published: 21 October 2019

\begin{abstract}
There is growing interest in determining the unidentified peaks within a sample spectra besides the analytes of interest. Availability of reference standards and hyphenated instruments has been a key and limiting factor in the rapid determination of emerging pollutants in the environment. In this work, polar compounds were silylated and analyzed with gas chromatography mass spectrometry (GC-MS) to determine the abundant fragments within the single ion monitoring (SIM) mode and methodology. Detection limits and recoveries of the compounds were established in river water, wastewater, biosolid and sediment matrices. Then, specific types of polar compounds that are classified as emerging contaminants, pharmaceuticals and personal care products, in the environment were targeted in the Mgeni and Msunduzi Rivers. We also performed suspect and non-target analysis screening to identify several other polar compounds in these rivers. A total of 12 compounds were quantified out of approximately 50 detected emerging contaminants in the Mgeni and Msunduzi Rivers. This study is significant for Africa, where the studies of emerging contaminants are limited and not usually prioritized.
\end{abstract}

Keywords: suspect and non-target analysis; GC-MS; emerging pollutants; pharmaceutical and personal care products

\section{Introduction}

Many polar micro-contaminants such as illicit drugs, personal care products, plasticizers, pharmaceuticals and flame retardants exist in the environment, as evidenced from various studies [1-5]. Additionally, several transformation products can be formed from these various micro-contaminants, of which just a few have been identified [6-8]. Transformation products may be toxic compared to the parent compound [9]. The level of toxicity maybe further exacerbated by the presence of potentially harmful unknown compounds that are simultaneously present in the environment together with priority contaminants. Methods on how to account for these various micro-contaminants and include such compounds in the analysis of environmental samples is of growing interest. Moreover, the existence of organic matter such as humic acid can obstruct the pre-concentration of analytes, mass spectrometry ionization and determination of anthropogenic compounds.

In the literature, there are three approaches that are normally used for the analysis of compounds: target, suspect and non-target analytes [10-12]. Targeted methods are constrained by the availability of analytical standards, accompanied with costly reference standards, and therefore the identification of 
emerging contaminants within the environment may be delayed. Suspect screening has the advantage of using databases with known analyte structural properties and molecular ion formulae, which are computationally compared to mass spectrometry spectral data to give potential similarities to the compound of interest. The third approach, non-target analysis, is a growing focus but more challenging to carry out because no prior information is usually available [13-15]. The environmental samples could contain thousands of peaks $[16,17]$. As a result, steps need to be taken to decrease the amount of peaks to a manageable number, calculate suitable molecular formulae, determine the isotopic patterns, and perform defect analysis of the mass defect and time prediction of the retention time $[14,18,19]$.

Based on its selectivity or accuracy, mass spectrometry is becoming the designated technique to detect and identify anonymous compounds in the environment [20]. The technique is based on correlation of the fragmentation pattern of mass spectra stored in the gas chromatography mass spectrometry (GC-MS) libraries. However, application of GC-MS in full-scan screening mode leads to low sensitivity/detection limits, poor selectivity and detection of many peaks in a sample, leading to false reporting of environmental data [21]. Moreover, most emerging pollutants are polar and GC-MS is not usually suitable for their analysis in environmental matrices. Recently, the development of precise high-resolution mass spectrometry (HRMS) opened a new paradigm in analytical processing or handling data for non-targeted compounds. Multi-residue analytical techniques are playing major roles to provide full information about overall environmental contamination, which can fast-track the identification of unknown compounds in the environment at large [10,19,22,23].

The combination of GC-MS, derivatization of samples and detection in single ion monitoring (SIM) mode may offer some advantages when compared to HRMS methods in terms of selectivity, precision, sensitivity, simplicity, cost and interference due to matrix effects. However, the lack of libraries for the derivatized compounds in the SIM mode compared to the full-scan mode has resulted in this method being overlooked for the screening of environmental samples in favor of HRMS. In general, the most abundant fragment ion results from fragmentation processes that form the most stable products, which determines the detectability of the analyte. The abundance of fragment ions of interest are affected by their stability. Silylated compounds produce informative and stable fragments, which enhances the detection limits of the GC-MS. In most situations, silylation reactions generate only the desired derivatives. However, the mass spectra of many silylated compounds may not be available in common mass spectral libraries. Other side reactions due to derivatization, such as alkylation and acylation, produce undesired compounds, and the use of Lewis acids as catalysts in aqueous solutions can affect the longevity of the column packing and decrease the instrument sensitivity. GC-MS methods are known to be cheap and robust if they are developed properly. These methods are needed in our technologically advanced societies, where approximately 100,000 chemical substances are used daily, with a large number of new compounds being discovered and registered every year [16]. Because of the potential negative environmental and/or health impact connected with contact to some of these chemicals, data regarding the presence of known and unknown compounds in the environment must be provided and regularly updated.

In this work, various pharmaceuticals and personal care products (PPCPs) were silylated, and abundant fragments were identified and used in single ion monitoring mode for quantification. As the publically available libraries/databases, such as National Institute of Standards and Technology (NIST), contain fragments obtained from scanning mode, an in-house database was built based on silylated abundant ions by injecting derivatized standards in the GC-MS. Then, quantitative and qualitative analysis of polar compounds that can be classified as emerging contaminants was carried out on samples from two rivers in South Africa using the single ion monitoring GC-MS method. In addition, suspect and non-target analyses were performed to identify some more contaminants in the environmental samples. NIST was used for searching and prediction of unknown compounds within samples. We were able to screen samples from portable water, wastewater, biosolid and sediment samples from the Mgeni and Msunduzi Rivers over a 1-year period. 


\section{Materials and Methods}

Glassware and amber bottles were cleaned with phosphate-free soap bought from Dynachem (Durban, South Africa) and were left in the acid bath for a day. Then all glassware (Searle, Vervaardig, South Africa) were further washed with $5 \%$ dichloromethylsilane, finally rinsed with methanol, and then placed in the oven (Prolab, Durban, South Africa) at $60{ }^{\circ} \mathrm{C}$ for $12 \mathrm{~h}$. Micro-volumes were transferred by a micropipette plus kit bought from Dragon lab (Beijing, China) ranging between 0.5 to $1000 \mu \mathrm{L}$. All glass fibre filters were purchased from Pall Corporation (Johannesburg, South Africa). Extraction cartridges (Oasis HLB 20 cc (1 g and $60 \mathrm{mg})$ LP, tC18 environmental cartridge sepak-pak and sepak-pak plus CN cartridge) were bought through Microsep (Durban, South Africa), a local supplier of Waters Corporation (Milford, MA, USA) products in South Africa. A Shimadzu QP2010 SE GC-MS (Kyoto, Japan) equipped with an autosampler and autoinjector (AOC-20i) (AOC-20s) was used for analysis. The capillary column, Crossbond 5\% diphenyl/95\% dimethyl polysiloxane (intercap 5 Sil MS $0.25 \mathrm{mmL}$. D × $30 \mathrm{M} \mathrm{df}=0.25 \mu \mathrm{m}$, non-polar) purchased from Restek (Bellefonte, PA, USA) was used for GC separation. Experiments were conducted at a room temperature of $20^{\circ} \mathrm{C}$.

\subsection{Preparation of Stock Solutions}

Working solutions of each standard surrogate standard cinnamic acid, 3-phenylprop-2-enoic acid internal standard (IS) 2-chlorobenzoic acid, and injector standard 4, 4-di-tert-butylbiphenyl (1000 $\mu \mathrm{g} / \mathrm{L})$ were dissolved in methanol and kept at $4{ }^{\circ} \mathrm{C}$.

\subsection{Sampling of Sediments and Water}

The samples of river water and wastewater were collected in $2.5 \mathrm{~L}$ amber glass bottles. No preservatives were added, the samples were kept in a cooler box at $4-6{ }^{\circ} \mathrm{C}$ and transferred into the laboratory for further analysis. All sampling points were along the Msunduzi and Mgeni Rivers as shown in Figure 1.

Sediment samples were taken, along the riverbed $(0-10 \mathrm{~cm}$ depth), from different sampling sites using the grab method and were covered with aluminum foil. Sediments were air dried at $30{ }^{\circ} \mathrm{C}$ for 3 days, then ground by hand in a ceramic mortar and pestle, and sieved through different layers of mesh to obtain a final particle size of $53 \mu \mathrm{m}(600,400,300,200,100,75$ and $53 \mu \mathrm{m})$ to ensure consistency and normalization of the sample. 


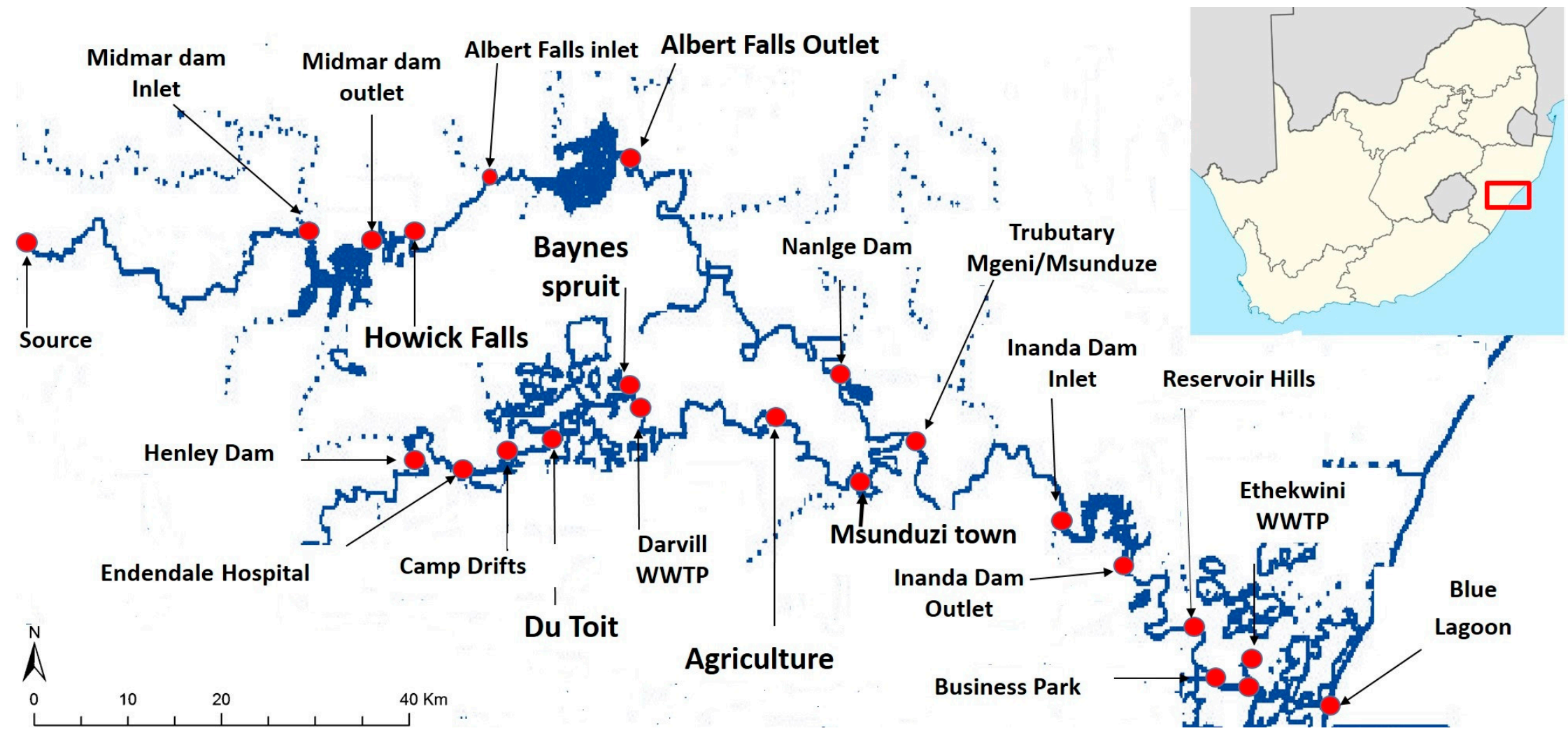

Figure 1. Sampling area of the Msunduzi and Mgeni Rivers in KwaZulu-Natal, South Africa. Grab samples were collected along all points indicated and analyzed using the developed method described in this work (map was drawn using GIS software (Caliper Corporation, Newton MA, United States of America) shape file). 


\subsection{Sampling of Biosolids}

Biosolid and wastewater samples were taken at the entrance of the wastewater treatment plants. The biosolid samples were partially concentrated solids separated from the sewage at wastewater treatment plants (WWTPs), as can be seen in Figure 1. These samples were dried under air and processed using the procedure described below to treat and extract analytes from sample matrices.

\subsection{Sample Extraction}

\subsubsection{Water}

Solid phase extraction (SPE) of liquid samples was done using an Oasis HLB cartridge (Waters, Milford, MA, USA) (1 g) at $\mathrm{pH} 2$ and $\mathrm{pH} 7$; $\mathrm{pH}$ was controlled by adding $1 \mathrm{M}$ of diluted sulphuric acid dropwise ( $\mathrm{pH}$ changes were recorded by a $\mathrm{pH}$ meter). The Oasis HLB cartridges were successively preconditioned by additions of $6 \mathrm{~mL}$ methanol, and ultra-pure water $(\mathrm{pH} 2$ or $\mathrm{pH}$ 7). Then $1 \mathrm{~L}$ of the sample was extracted/pre-concentrated using a flow rate between 5 to $10 \mathrm{~mL} \mathrm{~min}{ }^{-1}$. After drying the cartridge in air for $30 \mathrm{~min}$ under a gentle stream of nitrogen, the sample was eluted with a total of $9 \mathrm{~mL}$ of extraction solution (acetone/ethyl acetate 1:1 $6 \mathrm{~mL}$; methanol $1 \mathrm{~mL}$; acetonitrile $1 \mathrm{~mL}$; 1 dichloromethane $1 \mathrm{~mL}$ ).

\subsubsection{Sediments and Biosolids}

Sediment samples were subjected to an ultrasound extraction procedure, and each sediment sample was treated twice. In a typical treatment step, a mass of $10 \mathrm{~g}$ of sediment per sample (based on dry weight) was placed in a centrifuge tube $(50 \mathrm{~mL})$ with $10 \mathrm{~mL}$ of solution (ethyl acetate/acetone (1:1) $8 \mathrm{~mL}$ and water/acetonitrile (1:1) $2 \mathrm{~mL}$ ). The samples were initially shaken vigorously and then placed in an ultrasonic bath for $20 \mathrm{~min}$ at room temperature. In a centrifuge, the samples were subjected to a speed of $6000 \mathrm{rpm}$ for $20 \mathrm{~min}$ and the content was decanted into a silylated glass bottle. After centrifugation, extracts from two-treatment steps (on one sediment sample) were mixed before the clean-up/SPE procedure.

The mixed extracts obtained in the ultrasound-centrifugation step were evaporated to $0.5 \mathrm{~mL}$ in a glass vial under a nitrogen stream. The contents of the vial were transferred into a $250 \mathrm{~mL}$ glass bottle via rinsing with $0.5 \mathrm{~mL}$ methanol, were made to $200 \mathrm{~mL}$ with Millipore water, and the $\mathrm{pH}$ was controlled to $\mathrm{pH} 2$ or $\mathrm{pH} 7$ with $1 \mathrm{M}$ sulfuric acid. This solution was percolated through the Oasis HLB cartridge (60 mg), which was previously conditioned and eluted as described in Section 2.4.1.

\subsubsection{Recoveries and Procedural Blanks}

Spiked sediments or biosolid samples were prepared by adding $10 \mu \mathrm{L}$ solutions ( $10 \mathrm{mg} / \mathrm{L})$ of the target analytes in ethyl acetate to an exact $10 \mathrm{~g}$ sample and the solvents were evaporated in darkness overnight under $15^{\circ} \mathrm{C}$ to avoid degradation of the analytes by light. The concentration of analytes in the samples after drying was $10 \mathrm{ng} / \mathrm{g}$. The blank samples were prepared to determine the absolute recoveries.

Spiked water samples were prepared by adding $100 \mu \mathrm{L}$ solution $(10 \mathrm{mg} / \mathrm{L})$ of target analytes into $1 \mathrm{~L}$ of distilled water, river water or wastewater. The final concentration of target compounds in $1 \mathrm{~L}$ was $1 \mu \mathrm{g} / \mathrm{L}$. Blank water samples were analyzed to determine absolute recoveries.

\subsection{Derivatization}

The extracts were re-dissolved into $100 \mu \mathrm{L}$ of NIST $+1 \%$ TMCS, gently mixed while the vial was closed, and permitted to undergo a reaction at room temperature for $2 \mathrm{~min}$. Then, the mixture was transferred into an oven to react for $30 \mathrm{~min}$ at $70{ }^{\circ} \mathrm{C}$. After the derivatization process, the extracts were diluted up to $0.5 \mathrm{~mL}$ volume with acetonitrile and $2 \mu \mathrm{L}$ of the derivatized sample extracted residue 
was injected into the GC-MS. Optimization of the derivatization procedure was done in our previously published work [24].

\subsection{GC-MS Analysis}

Selected suspect, target and non-target contaminants were detected by Shimadzu QP2010 SE equipped with auto-injector. At the beginning, the temperature of the column oven was kept at $70^{\circ} \mathrm{C}$, the injector-port temperature was maintained at $250{ }^{\circ} \mathrm{C}$, and $2 \mu \mathrm{L}$ sample extract residues were injected in the split-less mode. Helium was used as the carrier gas at a flow rate of $8.0 \mathrm{Ml} / \mathrm{min}$ and pressure of $61.5 \mathrm{KPa}$. The temperature was initially held at $70^{\circ} \mathrm{C}$ for $1 \mathrm{~min}$, then increased at a rate of $30^{\circ} \mathrm{C} / \mathrm{min}$ to $190^{\circ} \mathrm{C}$ (kept for $\left.1 \mathrm{~min}\right)$, then ramped at $15^{\circ} \mathrm{C} / \mathrm{min}$ to $230^{\circ} \mathrm{C}(3 \mathrm{~min})$ and lastly ramped at $30^{\circ} \mathrm{C} / \mathrm{min}$ to $270^{\circ} \mathrm{C}$, and then held for $1 \mathrm{~min}$. The interface between the oven and ion source chamber was set at $200^{\circ} \mathrm{C}$, which was the same as the ion-source temperature. Filament electron energy was fixed at $70 \mathrm{eV}$. The ion trap detector (ITD) parameters were set as follows: scan mass range between 50-850 m/z, $4 \mathrm{~min}$ solvent cut-off and $30 \mathrm{~min}$ run-time. Single ion monitoring (SIM) mode was performed for detection of selected analytes. This GC-MS method was based on our initial work, and quantification of acidic drugs in surface waters [24].

\subsection{Data Analysis (Including Software)}

The GC-MS system was controlled using GCMS solution software (Version 4.11 SU1) from Shimadzu, Kyoto, Japan. The obtained data were analyzed using Postrun, which is an application manager of the GCMS solution. Postrun software allowed peak detection, assisted by automatic library searching, and similarity checks after integration. Integration is based on the peak area, height and rejection parameters, such as signal to noise ratio, slope, and drift. The instrument was operated in both full scan and single ion monitoring (SIM) mode for qualitative and quantitative analysis, respectively. Only analytes with an $\mathrm{m} / \mathrm{z}$ between 30 and 850 were monitored and reported. The spectra measured by the instrument were matched with NIST (Version 11) library spectra based on these parameters: minimum similarity, search depth, hit number and retention index. The similarity index is a quantitative expression of the difference between the spectrum of an unknown sample and the spectrum recorded in a library as shown in Figure 2.

The similarity index (SI) is calculated using the equation below.

$$
\mathrm{SI}=\left(1-\frac{\sum_{\frac{m}{z}}\left\|\operatorname{lu}\left(\frac{m}{z}\right)-\operatorname{lt}\left(\frac{m}{z}\right)\right\|}{\sum_{\frac{m}{z}}\left\{\operatorname{lu}\left(\frac{m}{z}\right)+\operatorname{lt}\left(\frac{m}{z}\right)\right\}}\right) \times 100
$$

$\mathrm{lu}(\mathrm{m} / z)$ : relative spectrum intensity of the $m / z$ of the unknown mass spectrum.

$\operatorname{lt}(m / z)$ : relative spectrum intensity of the $m / z$ of a mass spectrum recorded in a library.

An SI of 100 indicates mass spectra that are identical, while an SI of 0 indicates spectra that are completely different as shown in Figure 2.

The search for a list of potential positive compounds was done by using the NIST database based on the trimethylsilyl (TMS) derivatives fragmentation pattern. 


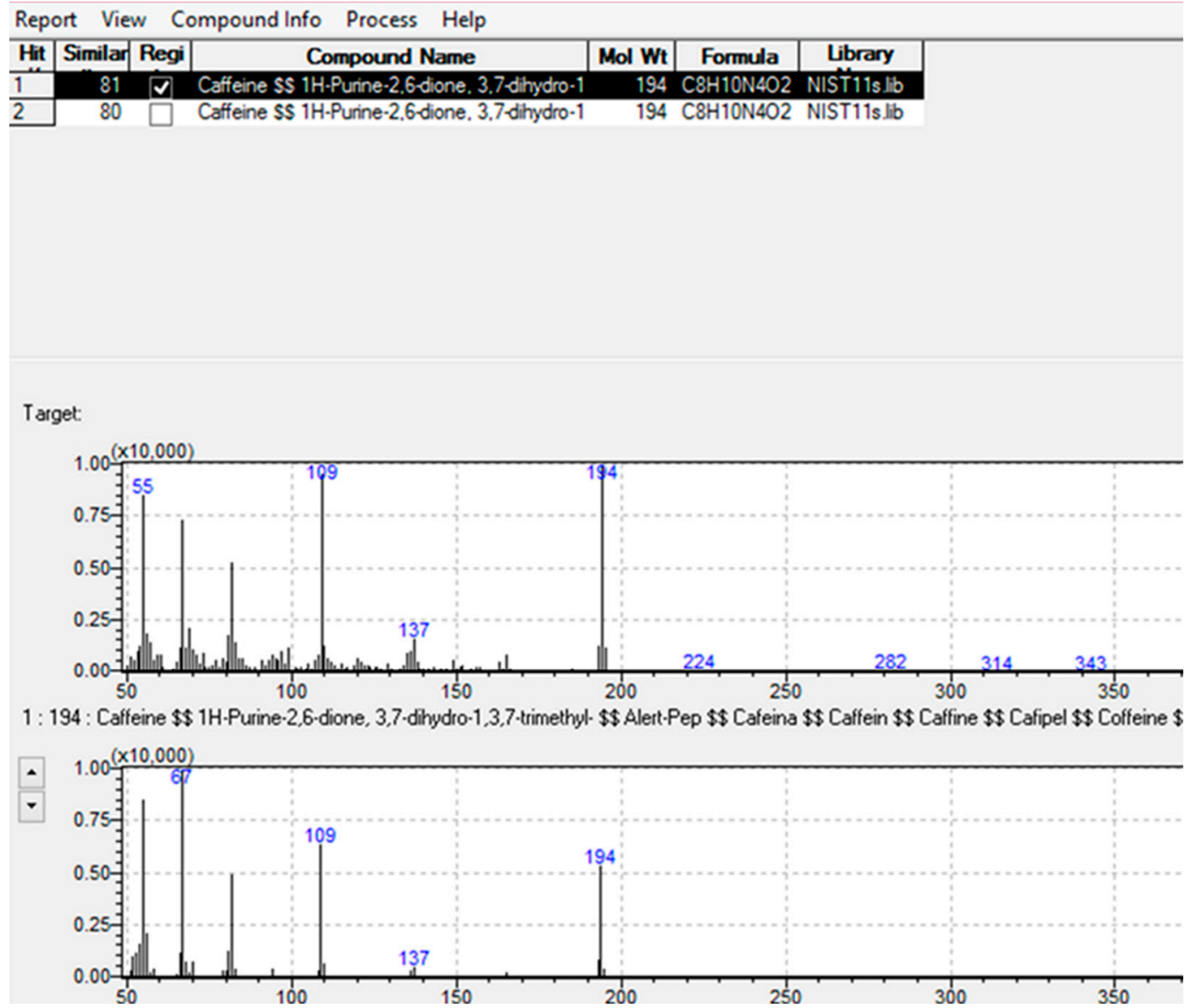

Figure 2. Comparison of measured caffeine spectra with NIST library spectra.

\section{Confirmation of Standards}

All target compounds were derivatized and injected into the GC-MS. The measured analytical information, such as retention time, fragmentation pattern and SIM ion, are presented in Table 1. This information was used to establish acceptable the similarity and rejection index of the methods as shown in Figure 2. The similarity index for caffeine was established to be $80 \%$ after injection of the caffeine standard and NIST library search was performed to identify the compound. The similarity index for most derivatized compounds matching with the spectra within the NIST library ranged from $60-100 \%$, which was wide due to the added silylil group. The GC-MS results for selected compounds are included in the Supplementary Section. 
Table 1. Derivatized pharmaceutical and personal care GC-MS products obtained by injecting target standards.

\begin{tabular}{|c|c|c|c|c|c|c|}
\hline $\begin{array}{l}\text { Target Analytes TMS } \\
\text { Derivative }\end{array}$ & Type & $\begin{array}{l}\text { Chemical Formula } \\
\text { Trimethylsilyl (TMS) }\end{array}$ & $\begin{array}{c}\text { Retention } \\
\text { Time Minutes }\end{array}$ & $\begin{array}{l}\text { Fragment Pattern TMS Derivative } \\
\qquad(\mathrm{m} / \mathrm{z})\end{array}$ & $\begin{array}{c}\text { Selected Ion } \\
\text { Monitored }(m / z)\end{array}$ & $\begin{array}{l}\text { Similarity } \\
\text { Index }\end{array}$ \\
\hline Methamphetamine & Illicit drug & $\mathrm{C}_{10} \mathrm{H}_{15} \mathrm{~N}$ & 5.450 & $58,91,134,148$ & 58,91 & 84 \\
\hline Salicylic acid & NSAID & $\mathrm{C}_{7} \mathrm{H}_{6} \mathrm{O}_{3}$ & 6.345 & $73,135,193,209,267$ & 135,267 & 82 \\
\hline Acetylsalicylic acid & NSAID & $\mathrm{C}_{9} \mathrm{H}_{8} \mathrm{O}_{4}$ & 6.467 & $65,73,120,195,210,268$ & 120,195 & 95 \\
\hline Nalidixic acid & Antibiotic & $\mathrm{C}_{12} \mathrm{H}_{12} \mathrm{~N}_{2} \mathrm{O}_{3}$ & 6.914 & $73,116,162,180,236,301$ & 180,236 & 89 \\
\hline Ibuprofen & NSAID & $\mathrm{C}_{13} \mathrm{H}_{18} \mathrm{O}_{2}$ & 7.105 & $73,117,160,191,263,278$ & 117,160 & 80 \\
\hline Propylparaben & Antifungal agent & $\mathrm{C}_{10} \mathrm{H}_{12} \mathrm{O}_{3}$ & 7.458 & $73,116,162,180,236,301,251$ & 162,236 & 80 \\
\hline Phenacetin & Analgesic & $\mathrm{C}_{10} \mathrm{H}_{13} \mathrm{NO}_{2}$ & 7.800 & $53,109,137,179,209$ & 109,179 & 96 \\
\hline Acetaminophen & NSAID & $\mathrm{C}_{8} \mathrm{H}_{9} \mathrm{NO}_{2}$ & 8.000 & $73,106,166,181,223$ & 181,223 & 88 \\
\hline Phenoxyphenol & Standard & $\mathrm{C}_{12} \mathrm{H}_{10} \mathrm{O}_{2}$ & 8.250 & $73,122,150,185,258$ & 150,258 & 91 \\
\hline Morphine & Opioid analgesic & $\mathrm{C}_{17} \mathrm{H}_{19} \mathrm{NO}_{3}$ & 8.450 & $75,103,119,174,204,232,285$ & 232,204 & 81 \\
\hline Caffeine & Stimulant & $\mathrm{C}_{8} \mathrm{H}_{10} \mathrm{~N}_{4} \mathrm{O}_{2}$ & 8.912 & 109,194 & 109,194 & 81 \\
\hline Naproxen & NSAID & $\mathrm{C}_{14} \mathrm{H}_{14} \mathrm{O}_{3}$ & 10.685 & $173,41,185,243,302$ & 185,243 & 88 \\
\hline procaine & Anaesthetic & $\mathrm{C}_{13} \mathrm{H}_{20} \mathrm{~N}_{2} \mathrm{O}_{2}$ & 10.950 & $58,86,164$ & 58,86 & 81 \\
\hline Triclosan & Disinfectant & $\mathrm{C}_{12} \mathrm{H}_{7} \mathrm{Cl}_{3} \mathrm{O}_{2}$ & 11.250 & $109,185,200$ & 109,200 & 95 \\
\hline Meclofenamic acid & NSAID & $\mathrm{C}_{14} \mathrm{H}_{11} \mathrm{Cl}_{2} \mathrm{NO}_{2}$ & 11.990 & $73,152,208,223,313,180$ & 223,313 & 95 \\
\hline Ketoprofen & NSAID & $\mathrm{C}_{16} \mathrm{H}_{14} \mathrm{O}_{3}$ & 12.105 & $73,105,165,179,253,282,311$ & 282,311 & 88 \\
\hline Diclofenac & NSAID & $\mathrm{C}_{14} \mathrm{H}_{11} \mathrm{Cl}_{2} \mathrm{NO}_{2}$ & 12.806 & $73,93,151,214,277,367$ & 214,367 & 91 \\
\hline Carbamazepine & Anticonvulsant & $\mathrm{C}_{15} \mathrm{H}_{12} \mathrm{~N}_{2} \mathrm{O}$ & 13.654 & $63,96,165,193,236$ & 193,236 & 88 \\
\hline Chloramphenicol & Antibiotic & $\mathrm{C}_{11} \mathrm{H}_{12} \mathrm{Cl}_{2} \mathrm{~N}_{2} \mathrm{O}_{5}$ & 13.921 & $73,93,147,208,225,361,451$ & 208,225 & 82 \\
\hline Cocaine & Illicit drug & $\mathrm{C}_{17} \mathrm{H}_{21} \mathrm{NO}_{4}$ & 14.530 & $77,82,152,182,272,303$ & 82,182 & 91 \\
\hline Procainamide & Transformation & $\mathrm{C}_{11} \mathrm{H}_{26} \mathrm{NO}_{2}$ & 15.450 & $85,99,192$ & 86,99 & 88 \\
\hline 2-phenylindolizine & Metabolite & $\mathrm{C}_{14} \mathrm{H}_{11} \mathrm{~N}$ & 15.960 & $63,96,165,193$ & 165,193 & 80 \\
\hline Sulfamethoxazole & Antibiotic & $\mathrm{C}_{10} \mathrm{H}_{11} \mathrm{~N}_{3} \mathrm{O}_{3} \mathrm{~S}$ & 16.500 & $65,92,156,189,253$ & 92,156 & 91 \\
\hline Chlorpromazine & Antipsychotic & $\mathrm{C}_{17} \mathrm{H}_{19} \mathrm{ClN}_{2} \mathrm{~S}$ & 17.605 & $58,214,232,272,315$ & 58,214 & 94 \\
\hline Lactose & Metabolite & $\mathrm{C}_{36} \mathrm{H}_{86} \mathrm{O}_{16}$ & 18.560 & $73,103,147,204,243,319,521$ & 204,243 & 81 \\
\hline Sulfamethazine & Antibiotic & $\mathrm{C}_{12} \mathrm{H}_{14} \mathrm{~N}_{4} \mathrm{O}_{2} \mathrm{~S}$ & 20.052 & $92,108,156,213,277$ & 92,213 & 95 \\
\hline Clozapine & Antipsychotic & $\mathrm{C}_{18} \mathrm{H}_{19} \mathrm{ClN}_{4}$ & 21.750 & $70,99,164,192,243,268,326$ & 192,243 & 93 \\
\hline
\end{tabular}


This analytical extraction method was derived from our previous work, which was based on the analysis of acidic drugs and personal care products (PCPs) in both solid and water samples taken along the Mgeni and Msunduzi Rivers [1,24-26]. A number of studies have employed acetonitrile and methanol to extract various drug residues [27-30]. However, the acetone/ethyl acetate solvent system was preferred over methanol and acetonitrile because these solvents extracted a large number of matrix components, which complicated identification of known and unknown compounds in the samples [31,32]. The clean-up step played a major role when compounds with different physicochemical properties were extracted. An Oasis HLB cartridge was used over cyno and environmental cartridges because the Oasis HLB permitted adjustment of the $\mathrm{pH}$ over a wide range to retain different classes of compounds, which was not possible with the later cartridges. As a large number of emerging contaminants are polar and contain heteroatoms such as oxygen, the Oasis HLB cartridge captured a broad class of polar compounds besides the target contaminants. The recovery studies were performed with Oasis HLB, and the results are presented in Table 2. All the target analyte percentages were within the acceptable recoveries recommended by IUPAC [33]. The method detection limits were evaluated on river water, wastewater, biosolids and sediments spiked with target analytes. Spiking and extraction of samples was undertaken as described in the experimental section. Limit of detection (LOD) and limit of quantification (LOQ) for the target method were established by repeating the analysis 10 times at low concentration levels in four different matrices, and the results are presented in Table 2. Equations (2) and (3) were used to calculate LOD and LOQ, where $\sigma$ is the standard deviation of the spiked sample, and $\mathrm{s}$ is the slope of the calibration curve [34].

$$
\begin{aligned}
\mathrm{LOD} & =\frac{\sigma}{s} \times 3 \\
\mathrm{LOQ} & =\frac{\sigma}{s} \times 10
\end{aligned}
$$

The LOD and LOQ values for river water and wastewater samples was higher than the sediment and biosolid limits. In addition, the Oasis cartridge absorbed more compounds, such as primary or secondary amines, which resulted in several of these compounds being detected [35]. Moreover, recovery of antibiotics was poor, and as a result, this class of compounds were not quantified in this study, except chloramphenicol. 
Table 2. Percent recovery, limit of detection and limit of quantification of derivatized compounds after spiking samples and performed recoveries.

\begin{tabular}{|c|c|c|c|c|c|c|c|c|c|c|c|c|}
\hline \multirow{2}{*}{ Target Analytes } & \multicolumn{4}{|c|}{ \%Recovery } & \multicolumn{4}{|c|}{ Limit of Detection (LOD) } & \multicolumn{4}{|c|}{ Limit of Quantification (LOQ) } \\
\hline & $\begin{array}{c}\text { River Water } \\
\%\end{array}$ & $\begin{array}{c}\text { Wastewater } \\
\%\end{array}$ & $\begin{array}{c}\text { Sediments } \\
\%\end{array}$ & $\begin{array}{c}\text { Biosolids } \\
\%\end{array}$ & $\begin{array}{c}\text { River Water } \\
\text { ng/L }\end{array}$ & $\begin{array}{c}\text { Wastewater } \\
\text { ng/L }\end{array}$ & $\begin{array}{l}\text { Sediments } \\
\mathrm{ng} / \mathrm{g}\end{array}$ & $\begin{array}{c}\text { Biosolids } \\
\text { ng/g }\end{array}$ & $\begin{array}{c}\text { River Water } \\
\text { ng/L }\end{array}$ & $\begin{array}{c}\text { Wastewater } \\
\text { ng/L }\end{array}$ & $\begin{array}{l}\text { Sediments } \\
\text { ng/g }\end{array}$ & $\begin{array}{c}\text { Biosolids } \\
\text { ng/g }\end{array}$ \\
\hline Salicylic acid & 70 & 65 & 100 & 105 & 41 & 51 & 0.04 & 0.17 & 135 & 164 & 0.15 & 0.56 \\
\hline Acetylsalicylic acid & 99 & 90 & 91 & 102 & 285 & 403 & 0.02 & 0.09 & 950 & 1333 & 0.07 & 0.03 \\
\hline Ibuprofen & 99 & 96 & 92 & 102 & 143 & 160 & 0.05 & 0.03 & 477 & 533 & 0.16 & 0.08 \\
\hline Propylparaben & 98 & 102 & 94 & 105 & 1000 & 1500 & 0.10 & 0.14 & 4000 & 3000 & 0.3 & 0.42 \\
\hline Phenacetin & 105 & 115 & 120 & 98 & 345 & 432 & 0.08 & 0.18 & 1151 & 1444 & 0.26 & 0.59 \\
\hline Caffeine & 96 & 104 & 92 & 107 & 100 & 400 & 0.35 & 0.1 & 300 & 1100 & 1.07 & 0.33 \\
\hline Naproxen & 82 & 80 & 66 & 112 & 75 & 101 & 0.08 & 0.03 & 248 & 333 & 0.280 & 0.104 \\
\hline Triclosan & 100 & 94 & 91 & 108 & 89 & 100 & 0.08 & 0.1 & 270 & 290 & 0.25 & 0.36 \\
\hline Meclofenamic acid & 103 & 106 & 85 & 121 & 82 & 111 & 0.11 & 0.14 & 272 & 368 & 0.38 & 0.46 \\
\hline Diclofenac & 90 & 93 & 103 & 98 & 484 & 559 & 0.09 & 0.55 & 1614 & 1864 & 0.31 & 1.8 \\
\hline Carbamazepine & 95 & 80 & 91 & 66 & 140 & 200 & 0.11 & 1.0 & 290 & 650 & 0.32 & 3.4 \\
\hline Chloramphenicol & 98 & 102 & 98 & 102 & 100 & 500 & 1.8 & 2.5 & 250 & 1400 & 5.5 & 7.6 \\
\hline
\end{tabular}




\section{Results and Discussion}

\subsection{Analysis of Environmental Samples: Target Analysis}

The identification, confirmation and quantification of contaminants at trace level concentrations required a high sensitivity and selectivity to overcome a complex background matrix from biosolids and wastewater samples. Due to a large range of compounds targeted and number of peaks detected in the environment, the GC-MS was operated in single ion monitored mode to get lower detection limits and improved selectivity.

\subsubsection{Quantification Analysis}

A range of studies have shown that monitoring only one ion fragment might result in false positive identifications of contaminants, and in this work, two ions were selected to be monitored and used in quantification of target analytes [21,36-39]. In addition, the information provided in Table 1 was used to further confirm the presence of targeted analytes and eliminate errors in identification. In total, 12 compounds were targeted in four matrixes. Approximately 38 river water samples were collected and analyzed. Salicylic acid was below the quantification level in these rivers. Phenacetin and naproxen were found in higher concentrations in the Mgeni River as shown in Table 3. While triclosan and propylparaben were high in the Msunduzi River. In general, the Msunduzi River had a higher concentration of personal care products and the Mgeni River had a higher concentration of pharmaceuticals. Acetylsalicylic acid was found in higher concentrations in sediments in both rivers, followed by caffeine as presented in Table 3. Hence, salicylic acid, a metabolite of acetylsalicylic acid, was quantified in sediments in both rivers. Personal care products, as expected, were high in the Msunduzi River, as it is surrounded by informal settlements without proper sanitation. A number of WWTPs discharge their effluent to the Mgeni River and the concentration of pharmaceuticals, as expected, was higher than in the Msunduzi River. Environmental concentration levels obtained in this study were within range of the data from the literature [17,40-42].

Approximately 16 wastewater and biosolid samples collected from WWTPs in both municipalities were analyzed for target analysis. Caffeine was found to be dominant in wastewater samples from WWTPs in the Pietermaritzburg and Durban municipalities, and these results are presented in Table 4. All target analytes were quantified in biosolids. Diclofenac existed in high concentration with a median of $12 \mathrm{ng} / \mathrm{g}$. Chloramphenicol, the only antibiotic quantified in the study, was found to range from ND to $16 \mathrm{ng} / \mathrm{g}$, with a median of $5.3 \mathrm{ng} / \mathrm{g}$, as shown in Table 4 . 
Table 3. Quantification of targeted contaminants in the Mgeni and Msunduzi Rivers.

\begin{tabular}{|c|c|c|c|c|c|c|c|c|}
\hline \multirow{4}{*}{ Target Analytes } & \multicolumn{4}{|c|}{ Mgeni River } & \multicolumn{4}{|c|}{ Msunduzi River } \\
\hline & \multirow{2}{*}{\multicolumn{2}{|c|}{$\begin{array}{c}\text { River Water (ng/L) } \\
\text { No. of Samples = } 24\end{array}$}} & \multirow{2}{*}{\multicolumn{2}{|c|}{$\begin{array}{c}\text { Sediments (ng/g) } \\
\text { No. of Samples }=48\end{array}$}} & \multirow{2}{*}{\multicolumn{2}{|c|}{$\begin{array}{c}\text { River Aater (ng/L) } \\
\text { No. of Samples = } 14\end{array}$}} & \multirow{2}{*}{\multicolumn{2}{|c|}{$\begin{array}{c}\text { Sediments (ng/g) } \\
\text { No. of Samples }=28\end{array}$}} \\
\hline & & & & & & & & \\
\hline & Range & Median & Range & Median & Range & Median & Range & Median \\
\hline Salicylic acid & ND-D & $\mathrm{D}$ & ND-40 & 1.4 & ND & ND & ND-3.43 & 0.28 \\
\hline Acetylsalicylic acid & ND-1130 & 70 & ND-200 & 32 & ND-D & $\mathrm{D}$ & ND-163 & 8.0 \\
\hline Ibuprofen & ND-2570 & 3870 & ND-13 & 2.3 & ND-D & $\mathrm{D}$ & ND-1.3 & 0.50 \\
\hline Propylparaben & ND-D & $\mathrm{D}$ & ND-13 & 1.1 & ND-22,000 & 7000 & ND-31 & 5.0 \\
\hline Caffeine & ND-D & $\mathrm{D}$ & ND-128 & 2.0 & ND-15,000 & 4500 & ND-89 & 1.9 \\
\hline Naproxen & ND-59,000 & 2300 & ND-15 & 0.98 & ND-2380 & 580 & ND-D & $\mathrm{D}$ \\
\hline Triclosan & ND-5000 & 2000 & ND-79 & 3.3 & ND-20,000 & 2500 & ND-43 & 4.9 \\
\hline Meclofenamic acid & ND-23,800 & 4201 & ND-4.0 & 0.98 & ND & ND & ND-2.8 & 1.0 \\
\hline Diclofenac & ND-1010 & 370 & ND-3.75 & 0.91 & ND & ND & ND-8.0 & 1.9 \\
\hline Carbamazepine & ND-D & $\mathrm{D}$ & ND-12 & 1.3 & ND-D & $\mathrm{D}$ & ND-4.7 & 2.0 \\
\hline Chloramphenicol & ND-D & $\mathrm{D}$ & ND-5.0 & 0.54 & ND-D & $\mathrm{D}$ & ND-19 & 5.0 \\
\hline
\end{tabular}


Table 4. Quantification of target compounds in wastewater and biosolids at wastewater treatment plants.

\begin{tabular}{ccccc}
\hline & \multicolumn{2}{c}{ Wastewater Treatment Plants } \\
\cline { 2 - 4 } Target Analytes & \multicolumn{2}{c}{ Wastewater (ng/L) } & Biosolids (ng/g) \\
\cline { 2 - 4 } & \multicolumn{2}{c}{ No. of Samples = 16 } & No. of Samples = 16 \\
\cline { 2 - 4 } & Range & Median & ND-55 & Median \\
\hline Salicylic acid & ND-66,000 & 820 & ND-221 & 2.3 \\
Acetylsalicylic acid & ND & ND & ND-27 & 29 \\
Ibuprofen & ND-17,600 & 3000 & ND-28 & 2.5 \\
Propylparaben & ND-12,000 & 6200 & ND-40 & 4.0 \\
Phenacetin & ND-19,500 & 10 & ND-173 & 24 \\
Caffeine & D-15,000 & 7000 & ND-13 & 3.0 \\
Naproxen & ND-D & ND-3.2 & 0.94 \\
Triclosan & ND-30,000 & ND-86 & 8.0 \\
Meclofenamic acid & ND-2380 & 5000 & ND-206 & 12 \\
Diclofenac & ND-10,200 & N80 & ND-5.5 & 1.1 \\
Carbamazepine & ND-D & D & ND-16 & 5.3 \\
Chloramphenicol & ND-D & D & & 20 \\
\hline
\end{tabular}

$\mathrm{ND}=$ not detected, $\mathrm{D}=$ detected .

\subsubsection{Qualitative Analysis}

Databases and libraries contain many spectral data for compounds, which can be used to qualitatively analyze samples. The compounds are listed in Table 5. Their standards were prepared, derivatized, and injected into the GC-MS. The fragmentation pattern and chromatic information is listed in Table 1. The $\mathrm{R}^{2}$ values for their calibration curves was below 0.9 and not satisfactory $[33,34]$. This was attributed to the difficulty in silylating amines due to steric hindrance. As a result, these compounds could not be quantified, and instead were qualitatively analyzed. Absolute recoveries were performed by spiking samples with $1 \mu \mathrm{g} / \mathrm{L}$ of these compounds. Percent recovery was calculated by subtracting blanks divided by $1 \mathrm{mg} / \mathrm{L}$ injected standard equivalent of $1 \mu \mathrm{g} / \mathrm{L}$ after extraction and pre-concentration. All recoveries ranged from $60-120 \%$, limit of detection was taken as $1 \mu \mathrm{g} / \mathrm{L}$ for liquid samples and $10 \mathrm{ng} / \mathrm{g}$ for solid samples. Out of 14 analyzed, 13 were detected, and the only compound not found was procainamide as shown in Table 5. Most target analytes showed positive identification in biosolids compared to river water and wastewater samples.

Table 5. Qualitative analysis of silylated target compounds in the Msunduzi and Mgeni Rivers.

\begin{tabular}{cccccc}
\hline Target Analytes & $\begin{array}{c}\text { Schymanski } \\
\text { Assessment Level [43] }\end{array}$ & River Water & Wastewater & Sediments & Biosolids \\
\hline Acetaminophen & 1 & Detected & Detected & Detected & Detected \\
Ketoprofen & 1 & Detected & Detected & Detected & Detected \\
Sulfamethoxazole & 1 & Detected & - & - & - \\
Nalidixic acid & 1 & Detected & Detected & - & - \\
Sulfamethazine & 1 & - & - & - & Detected \\
Chlorpromazine & 1 & - & - & - & Detected \\
Clozapine & 1 & - & - & - & Detected \\
Procaine & 1 & - & - & - & Detected \\
Cocaine & 1 & - & Detected & - & Detected \\
Methamphetamine & 1 & Detected & Detected & Detected & Detected \\
Morphine & 1 & Detected & Detected & Detected & Detected \\
2-phenylindolizine & 1 & - & Detected & - & Detected \\
Lactose & 1 & - & - & - & - \\
Procainamide & 1 & - & - & - & - \\
\hline
\end{tabular}




\subsection{Suspect Analysis}

In contrast to target analysis, the suspects screening approach (see Table 6) did not rely on reference standards for identification of contaminants in samples. The peaks that were not target analytes, and eluted close to target analytes, were identified by using a NIST library search as described in Section 2.7 .

With the help of the NIST library, measured spectra were matched and approximately 14 unknown peaks from the samples were identified as shown in Table 6. Among the identified peaks was the compound codeine, which is an active ingredient in cough syrup. This compound currently falls under the category of a drug of abuse in South Africa, because of its prevalence amongst illicit drug users. Clofibric acid, a metabolite of many lipid-based drugs, was detected in almost all matrices, specifically river water, wastewater and biosolids, and the results are presented in Table 6.

\subsection{Non-Target Analysis}

The compounds presented in Table 7 were analyzed without any prior knowledge of their existence in the environment. Because this study was undertaken to analyze PCPPs in the Msunduzi and Mgeni Rivers. The detected compounds in these rivers did not fall under the classification of PCPPs. Many of these contaminants were detected in wastewater and river water, more so than in biosolids and sediments as shown in Table 7. This was attributed to the fact that there were fewer interfering compounds in these matrices. Only a few compounds were identified in biosolids and sediments, although several peaks were detected in these matrices. This was attributed to the complexity of the biosolid and sediment matrices, which hindered the identification of compounds without prior knowledge of spectral behavior and other parameters such as retention indexes. The classes of these non-target compounds were hormones, paint, plasticizers, UV filters and flame retardants. There is a scarcity of information on the presence of these types of compounds in this part of the world. Detection of these contaminants will serve as motivation to prioritize further work on detection and quantification of hormones, flame retardants and plasticizers in the African environment at large. 
Table 6. Suspect analysis of pharmaceutical and personal care products in the Msunduzi and Mgeni Rivers.

\begin{tabular}{|c|c|c|c|c|c|c|c|c|}
\hline Suspect Analytes & $\begin{array}{c}\text { Schymanski } \\
\text { Assessment Level [43] }\end{array}$ & $\begin{array}{l}\text { Chemical } \\
\text { Formula }\end{array}$ & Fragment Pattern $m / z$ & River Water & Wastewater & Sediments & Biosolids & $\begin{array}{l}\text { Similarity } \\
\text { Index }\end{array}$ \\
\hline Clofibric acid & 2 & $\mathrm{C}_{10} \mathrm{H}_{11} \mathrm{ClO}_{3}$ & $39,99,128,130,214$ & Detected & Detected & - & Detected & 75 \\
\hline Codeine & 2 & $\mathrm{C}_{18} \mathrm{H}_{21} \mathrm{NO}_{3}$ & $115,162,214,229,299$ & - & Detected & - & - & 80 \\
\hline Oxazepam & 2 & $\mathrm{C}_{15} \mathrm{H}_{11} \mathrm{ClN}_{2} \mathrm{O}_{2}$ & $77,205,233,239,268$ & - & Detected & - & - & 76 \\
\hline Trimethoprim & 1 & $\mathrm{C}_{14} \mathrm{H}_{18} \mathrm{~N}_{4} \mathrm{O}_{3}$ & $123,200,243,259$ & - & - & - & Detected & 91 \\
\hline Nicotine & 2 & $\mathrm{C}_{10} \mathrm{H}_{14} \mathrm{~N}_{2}$ & $42,84,161$ & - & - & - & Detected & 75 \\
\hline Amphetamine & 1 & $\mathrm{C}_{9} \mathrm{H}_{13} \mathrm{~N}$ & $44,65,91,120$ & - & Detected & - & - & 95 \\
\hline Benzoylecgonine & 1 & $\mathrm{C}_{16} \mathrm{H}_{19} \mathrm{NO}_{4}$ & $77,82,94,124,138$ & - & Detected & - & - & 95 \\
\hline Benzocaine & 2 & $\mathrm{C}_{16} \mathrm{H}_{11} \mathrm{NO}_{2}$ & $65,92,120,137,165$ & - & - & Detected & - & 80 \\
\hline Cotinine & 2 & $\mathrm{C}_{16} \mathrm{H}_{19} \mathrm{NO}_{4}$ & 98,176 & - & - & - & - & 79 \\
\hline Propranolol & 2 & $\mathrm{C}_{16} \mathrm{H}_{21} \mathrm{NO}_{2}$ & $30,72,115,144,331$ & Detected & - & - & - & 80 \\
\hline Azelaic acid & 2 & $\mathrm{C}_{9} \mathrm{H}_{14} \mathrm{Cl}_{2} \mathrm{O}_{2}$ & $55,83,124,152,367$ & Detected & - & - & - & 82 \\
\hline 4-Oxoisophorone & 2 & $\mathrm{C}_{9} \mathrm{H}_{12} \mathrm{O}_{2}$ & $39,68,96,152$ & - & Detected & - & - & 80 \\
\hline Musk xylene & 2 & $\mathrm{C}_{12} \mathrm{H}_{15} \mathrm{~N}_{3} \mathrm{O}_{6}$ & 43,282 & - & - & Detected & - & 80 \\
\hline 2-Pyrrolidone & 2 & $\mathrm{C}_{4} \mathrm{H}_{7} \mathrm{NO}$ & $73,142,157$ & - & & Detected & - & 81 \\
\hline 2-Phenoxyethanol & 2 & $\mathrm{C}_{8} \mathrm{H}_{10} \mathrm{O}_{2}$ & $77,94,138$ & Detected & & - & - & 79 \\
\hline
\end{tabular}


Table 7. Non-target analysis of new emerging contaminants in the Msunduzi and Mgeni River at Schymansaki assessment level 3.

\begin{tabular}{|c|c|c|c|c|c|c|c|c|}
\hline Non-Target Analytes & Source or Origin & $\begin{array}{l}\text { Chemical } \\
\text { Formula }\end{array}$ & Fragment Pattern $m / z$ & River Water & Wastewater & Sediments & Biosolids & $\begin{array}{l}\text { Similarity } \\
\text { Index }\end{array}$ \\
\hline Butyldiglycol & Paints & $\mathrm{C}_{8} \mathrm{H}_{18} \mathrm{O}_{3}$ & $57,100,132$ & Detected & Detected & - & - & 79 \\
\hline $\begin{array}{c}\text { 2-propanol, } \\
\text { 1-[1-methyl-2-(properyloxy)ether }\end{array}$ & - & $\mathrm{C}_{9} \mathrm{H}_{18} \mathrm{O}_{3}$ & $59,103,174$ & detected & - & - & - & 80 \\
\hline Nicotinic acid & Vitamin & $\mathrm{C}_{6} \mathrm{H}_{5} \mathrm{NO}_{2}$ & $51,91,136,195$ & - & Detected & - & - & 72 \\
\hline Phenylmalonic acid & - & $\mathrm{C}_{9} \mathrm{H}_{8} \mathrm{O}_{4}$ & $69,91,136$ & - & & & - & 88 \\
\hline $\begin{array}{l}\text { 2-ethyl-3-hydroxyhexyl } \\
\text { 2-methyl propanoate }\end{array}$ & - & $\mathrm{C}_{12} \mathrm{H}_{24} \mathrm{O}_{3}$ & $71,95,99,143,174$ & Detected & Detected & - & - & 79 \\
\hline Oxindole & Human metabolite & $\mathrm{C}_{8} \mathrm{H}_{7} \mathrm{NO}$ & $78,104,133$ & Detected & Detected & - & - & 81 \\
\hline 2,6-Dimethylphenyl isocyanide & Cyanobacteria & $\mathrm{C}_{9} \mathrm{H}_{9} \mathrm{NO}$ & $51,118,147$ & Detected & Detected & - & - & 60 \\
\hline Obtusifoliol & Hormone & $\mathrm{C}_{30} \mathrm{H}_{50} \mathrm{O}$ & $75,215,355,370,429$ & - & Detected & - & - & 75 \\
\hline Cholesterol & Hormone & $\mathrm{C}_{27} \mathrm{H}_{46} \mathrm{O}$ & $129,329,353,368,458$ & - & Detected & - & - & 88 \\
\hline Metolachlor & Herbicide, pesticide & $\mathrm{C}_{15} \mathrm{H}_{22} \mathrm{ClNO}_{2}$ & $91,162,238$ & Detected & & - & - & 95 \\
\hline Bisphenol A & Plasticizer & $\mathrm{C}_{15} \mathrm{H}_{16} \mathrm{O}_{2}$ & $119,213,228,372$ & - & - & - & - & 96 \\
\hline Triethyl phosphate & Plasticizer & $\mathrm{C}_{6} \mathrm{H}_{15} \mathrm{O}_{4} \mathrm{P}$ & $81,99,109,155,182$ & Detected & Detected & Detected & Detected & 81 \\
\hline Triethyl citrate & Plasticizer & $\mathrm{C}_{12} \mathrm{H}_{20} \mathrm{O}_{7}$ & $115,157,203,348$ & Detected & Detected & Detected & Detected & 82 \\
\hline Oxybenzone & UV filters & $\mathrm{C}_{14} \mathrm{H}_{12} \mathrm{O}_{3}$ & $51,77,151,227,300$ & & Detected & - & Detected & 80 \\
\hline Tris(2-chloroethyl) phosphate & Flame retardant & $\mathrm{C}_{6} \mathrm{H}_{12} \mathrm{Cl}_{3} \mathrm{O}_{4} \mathrm{P}$ & $63,143,205,249,253$ & Detected & - & - & - & 79 \\
\hline Triphenyl phosphate & Flame retardant & $\mathrm{C}_{18} \mathrm{H}_{15} \mathrm{O}_{4} \mathrm{P}$ & $77,169,233,233,326$ & - & - & - & Detected & 90 \\
\hline
\end{tabular}




\section{Conclusions}

Abundant fragments of silylated polar compounds were identified and used in GC-MS single ion monitoring mode to improve the sensitivity towards polar compounds in environmentally relevant concentrations. Obtained detection limits and recoveries allowed identification of these polar compounds in four compartments. Approximately 50 compounds were identified in river water, wastewater, sediment and biosolid samples collected from the Msunduzi and Mgeni Rivers. Out of the detected emerging contaminants, 12 were quantified mostly in sediments and biosolid matrices. Qualitative analysis was also performed and 14 compounds were found in the environment. Suspect and non-target analysis was also performed to identify unknown compounds using a readily available spectral library database, and 15 compounds previously not reported in the Msunduzi and Mgeni Rivers were found to exist. The use of GC-MS instrumentation and prior derivatization to identify up to 50 compounds successfully will serve as motivation to employ this method more often to study polar compounds in the environment. As GC-MS is more readily available in most laboratories in developing countries, more data will surface by using this method of detection.

Supplementary Materials: The following are available online at http://www.mdpi.com/1660-4601/16/20/4022/s1, Figure S1: Spectrum of derivatized chlorobenzoic acid. Obtained by injecting $2 \mu \mathrm{L}$ of standard solution into GC-MS after derivatization, Figure S2: Spectrum of derivatized cinnamic acid. Obtained by injecting $2 \mu \mathrm{L}$ of standard solution into GC-MS after derivatization, Figure S3: Spectrum of derivatized 4-phenoxyphenol. Obtained by injecting $2 \mu \mathrm{L}$ of standard solution into GC-MS after derivatization, Figure S4: Spectrum of derivatized acetylsalicylic acid. Obtained by injecting $2 \mu \mathrm{L}$ of standard solution into GC-MS after derivatization, Figure S5: Spectrum of derivatized ibuprofen. Obtained by injecting $2 \mu \mathrm{L}$ of standard solution into GC-MS after derivatization, Figure S6: Spectrum of phenacetin. Obtained by injecting $2 \mu \mathrm{L}$ of standard solution into GC-MS after derivatization. The lack of the silyl group indicated that this compound was not be derivatized, Figure S7: Spectrum of derivatized acetaminophen. Obtained by injecting $2 \mu \mathrm{L}$ of standard solution into GC-MS after derivatization, Figure S8: Spectrum of derivatized acetaminophen. Obtained by injecting $2 \mu \mathrm{L}$ of standard solution into GC-MS after derivatization, Figure S9: Spectrum of caffeine. Obtained by injecting $2 \mu \mathrm{L}$ of standard solution into GC-MS after derivatization. The lack of the silyl group indicated that this compound was not be derivatized, Figure S10: Spectrum of derivatized carbamazepine. Obtained by injecting $2 \mu \mathrm{L}$ of standard solution into GC-MS after derivatization. The lack of the silyl group indicated that this compound was not be derivatized, Figure S11: Spectrum of derivatized clozapine. Obtained by injecting $2 \mu \mathrm{L}$ of standard solution into GC-MS after derivatization. The lack of the silyl group indicated that this compound was not be derivatized, Figure S12: Spectrum of derivatized chlorpromazine. Obtained by injecting $2 \mu \mathrm{L}$ of standard solution into GC-MS after derivatization. The lack of the silyl group indicated that this compound was not be derivatized, Figure S13: Spectrum of sulfamethoxazole. Obtained by injecting $2 \mu \mathrm{L}$ of standard solution into GC-MS after derivatization. The lack of the silyl group indicated that this compound was not be derivatized, Figure S14: Spectrum of sulfamethazine. Obtained by injecting $2 \mu \mathrm{L}$ of standard solution into GC-MS after derivatization. The lack of the silyl group indicated that this compound was not be derivatized, Figure S15: Spectrum of derivatized chloramphenicol. Obtained by injecting $2 \mu \mathrm{L}$ of standard solution into GC-MS after derivatization, Figure S16: Spectrum of cocaine. Obtained by injecting $2 \mu \mathrm{L}$ of standard solution into GC-MS after derivatization. The lack of the silyl group indicated that this compound was not be derivatized, Figure S17: Spectrum of methamphetamine. Obtained by injecting $2 \mu \mathrm{L}$ of standard solution into GC-MS after derivatization. The lack of the silyl group indicated that this compound was not be derivatized, Figure S18: Spectrum of morphine. Obtained by injecting $2 \mu \mathrm{L}$ of standard solution into GC-MS after derivatization. The lack of the silyl group indicated that this compound was not be derivatized.

Author Contributions: B.P.G.; B.M.; G.B. and P.G.N. selected the sampling points and equally participated in the sampling campaign; B.P.G. performed laboratory work, methodology development, data analysis, validation, and writing-original draft preparation; B.M.; G.B. and P.G.N. contributed reagents, materials, and contributed to the data analysis. B.M.; G.B. and P.G.N. conceptualized the original project, acquired funding, administered the project, and jointly supervised. B.P.G.; B.M.; G.B. and P.G.N. improved the manuscript, and contributed equally to various drafts. All authors approved submission of the final draft.

Funding: This research was funded by the Water Research Commission of South Africa (Project No. K5/2215//3). B.P.G. gratefully acknowledges the National Research Foundation of South Africa for bursary support.

Acknowledgments: The authors acknowledge the School of Chemistry and Physics at the University of KwaZulu-Natal for access to facilities to carry out this research.

Conflicts of Interest: The authors declare no conflict of interest. The funders had no role in the design of the study; in the collection, analyses, or interpretation of data; in the writing of the manuscript, or in the decision to publish the results. 


\section{References}

1. Agunbiade, F.O.; Moodley, B. Pharmaceuticals as emerging organic contaminants in Umgeni River water system, KwaZulu-Natal, South Africa. Environ. Monit. Assess. 2014, 186, 7273-7291. [CrossRef] [PubMed]

2. Agunbiade, F.O.; Moodley, B. Occurrence and distribution pattern of acidic pharmaceuticals in surface water, wastewater, and sediment of the Msunduzi River, Kwazulu-Natal, South Africa. Environ. Toxicol. Chem. 2016, 35, 36-46. [CrossRef] [PubMed]

3. Albero, B.; Sánchez-Brunete, C.; García-Valcárcel, A.I.; Pérez, R.A.; Tadeo, J.L. Ultrasound-assisted extraction of emerging contaminants from environmental samples. Trends Anal. Chem. 2015, 71, 110-118. [CrossRef]

4. Dafouz, R.; Caceres, N.; Rodriguez-Gil, J.L.; Mastroianni, N.; de Alda, M.L.; Barcelo, D.; de Miguel, A.G.; Valcarcel, Y. Does the presence of caffeine in the marine environment represent an environmental risk? A regional and global study. Sci. Total Environ. 2018, 615, 632-642. [CrossRef]

5. Sopilniak, A.; Elkayam, R.; Rossin, A.V.; Lev, O. Emerging organic pollutants in the vadose zone of a soil aquifer treatment system: Pore water extraction using positive displacement. Chemosphere 2018, 190, $383-392$. [CrossRef]

6. Gavrilescu, M.; Demnerova, K.; Aamand, J.; Agathoss, S.; Fava, F. Emerging pollutants in the environment: Present and future challenges in biomonitoring, ecological risks and bioremediation. New Biotech. 2015, 32, 147-156. [CrossRef]

7. Prasse, C.; Wagner, M.; Schulz, R.; Ternes, T.A. Biotransformation of the Antiviral Drugs Acyclovir and Penciclovir in Activated Sludge Treatment. Environ. Sci. Technol. 2011, 45, 2761-2769. [CrossRef]

8. Souchier, M.; Benali-Raclot, D.; Benanou, D.; Boireau, V.; Gomez, E.; Casellas, C.; Chiron, S. Screening triclocarban and its transformation products in river sediment using liquid chromatography and high resolution mass spectrometry. Sci. Total Environ. 2015, 502, 199-205. [CrossRef]

9. Haakh, F. Emerging organic pollutants-A new challenge for drinking water supply? Wasser Abwasser 2010, 151, 740-748.

10. Gago-Ferrero, P.; Schymanski, E.L.; Bletsou, A.A.; Aalizadeh, R.; Hollender, J.; Thomaidis, N.S. Extended Suspect and Non-Target Strategies to Characterize Emerging Polar Organic Contaminants in Raw Wastewater with LC-HRMS/MS. Environ. Sci. Technol. 2015, 49, 12333-12341. [CrossRef]

11. Hernandez, F.; Ibanez, M.; Portoles, T.; Cervera, M.I.; Sancho, J.V.; Lopez, F.J. Advancing towards universal screening for organic pollutants in waters. J. Hazard. Mater. 2015, 282, 86-95. [CrossRef] [PubMed]

12. Sursyakova, V.V.; Burmakina, G.V.; Rubaylo, A.I. Strategy for non-target ionic analysis by capillary electrophoresis with ultraviolet detection. Anal. Bioanal. Chem. 2017, 409, 1067-1077. [CrossRef] [PubMed]

13. Gosetti, F.; Mazzucco, E.; Gennaro, M.C.; Marengo, E. Non-Target UHPLC/MS Analysis Emergency Contaminants Water; Springer International Publishing: Basel, Switzerland, 2015.

14. Hauler, C.; Vetter, W. A non-targeted gas chromatography/electron capture negative ionization mass spectrometry selected ion monitoring screening method for polyhalogenated compounds in environmental samples. Rapid Commun. Mass Spectrom. 2015, 29, 619-628. [CrossRef] [PubMed]

15. Plassmann, M.M.; Tengstrand, E.; Åberg, K.M.; Benskin, J.P. Non-target time trend screening: A data reduction strategy for detecting emerging contaminants in biological samples. Anal. Bioanal. Chem. 2016, 408, 4203-4208. [CrossRef] [PubMed]

16. Loos, R.; Gawlik, B.M.; Locoro, G.; Rimaviciute, E.; Contini, S.; Bidoglio, G. EU-wide survey of polar organic persistent pollutants in European river waters. Environ. Pollut. 2009, 157, 561-568. [CrossRef] [PubMed]

17. Schymanski, E.L.; Singer, H.P.; Slobodnik, J.; Ipolyi, I.M.; Oswald, P.; Krauss, M.; Schulze, T.; Haglund, P.; Letzel, T.; Grosse, S.; et al. Non-target screening with high-resolution mass spectrometry: Critical review using a collaborative trial on water analysis. Anal. Bioanal. Chem. 2015, 407, 6237-6255. [CrossRef] [PubMed]

18. Bade, R.; Causanilles, A.; Emke, E.; Bijlsma, L.; Sancho, J.V.; Hernandez, F.; de Voogt, P. Facilitating high resolution mass spectrometry data processing for screening of environmental water samples: An evaluation of two deconvolution tools. Sci. Total Environ. 2016, 569, 434-441. [CrossRef]

19. Solliec, M.; Roy-Lachapelle, A.; Sauve, S. Development of a suspect and non-target screening approach to detect veterinary antibiotic residues in a complex biological matrix using liquid chromatography/high-resolution mass spectrometry. Rapid Commun. Mass Spectrom. 2015, 29, 2361-2373. [CrossRef] 
20. Jernberg, J.; Pellinen, J.; Rantalainen, A.L. Qualitative nontarget analysis of landfill leachate using gas chromatography time-of-flight mass spectrometry. Talanta 2013, 103, 384-391. [CrossRef]

21. Baduel, C.; Mueller, J.F.; Tsai, H.H.; Ramos, M.J.G. Development of sample extraction and clean-up strategies for target and non-target analysis of environmental contaminants in biological matrices. J. Chromatogr. A 2015, 1426, 33-47. [CrossRef]

22. Castro, G.; Roca, M.; Rodriguez, I.; Ramil, M.; Cela, R. Identification and determination of chlorinated azoles in sludge using liquid chromatography quadrupole time-of-flight and triple quadrupole mass spectrometry platforms. J. Chromatogr. A 2016, 1476, 69-76. [CrossRef] [PubMed]

23. Tang, Y.N.; Xu, Y.; Li, F.; Jmaiff, L.; Hrudey, S.E.; Li, X.F. Nontargeted identification of peptides and disinfection byproducts in water. J. Environ. Sci. 2016, 42, 259-266. [CrossRef] [PubMed]

24. Gumbi, B.P.; Moodley, B.; Birungi, G.; Ndungu, P.G. Detection and quantification of acidic drug residues in South African surface water using gas chromatography-mass spectrometry. Chemosphere 2017, 168, 1042-1050. [CrossRef] [PubMed]

25. Gumbi, B.P.; Moodley, B.; Birungi, G.; Ndungu, P.G. Assessment of nonsteroidal anti-inflammatory drugs by ultrasonic-assisted extraction and GC-MS in Mgeni and Msunduzi river sediments, KwaZulu-Natal, South Africa. Environ. Sci. Pollut. Res. 2017, 24, 20015-20028. [CrossRef]

26. Matongo, S.; Birungi, G.; Moodley, B.; Ndungu, P. Pharmaceutical residues in water and sediment of Msunduzi River, KwaZulu-Natal, South Africa. Chemosphere 2015, 134, 133-140. [CrossRef] [PubMed]

27. Alvarez-Ruiz, R.; Andres-Costa, M.J.; Andreu, V.; Pico, Y. Simultaneous determination of traditional and emerging illicit drugs in sediments, sludges and particulate matter. J. Chromatogr. A 2015, 1405, 103-115. [CrossRef]

28. Antonić, J.; Heath, E. Determination of NSAIDs in river sediment samples. Anal. Bioanal. Chem. 2007, 387, 1337-1342. [CrossRef]

29. Archana, G.; Dhodapkar, R.; Kumar, A. Offline solid-phase extraction for preconcentration of pharmaceuticals and personal care products in environmental water and their simultaneous determination using the reversed phase high-performance liquid chromatography method. Environ. Monit. Assess. 2016, 188, 10616-10661. [CrossRef]

30. Castiglioni, S.; Zuccato, E.; Chiabrando, C.; Fanelli, R.; Bagnati, R. Mass spectrometric analysis of illicit drugs in wastewater and surface water. Mass Spectrom. Rev. 2008, 27, 378-394. [CrossRef]

31. González-Mariño, I.; Quintana, J.B.; Rodríguez, I.; Cela, R. Determination of drugs of abuse in water by solid-phase extraction, derivatisation and gas chromatography-ion trap-tandem mass spectrometry. J. Chromatogr. A 2010, 1217, 1748-1760. [CrossRef]

32. Wu, J.-W.; Chen, H.-C.; Ding, W.-H. Ultrasound-assisted dispersive liquid-liquid microextraction plus simultaneous silylation for rapid determination of salicylate and benzophenone-type ultraviolet filters in aqueous samples. J. Chromatogr. A 2013, 1302, 20-27. [CrossRef] [PubMed]

33. Thompson, M.; Ellison, S.L.; Wood, R. Harmonized guidelines for single-laboratory validation of methods of analysis (IUPAC Technical Report). Pure Appl. Chem. 2002, 74, 835-855. [CrossRef]

34. Gonzalez, A.G.; Herrador, M.A. A practical guide to analytical method validation, including measurement uncertainty and accuracy profiles. Trends Anal. Chem. 2007, 26, 227-238. [CrossRef]

35. Togola, A.; Budzinski, H. Analytical development for analysis of pharmaceuticals in water samples by SPE and GC-MS. Anal. Bioanal. Chem. 2007, 388, 627-635. [CrossRef] [PubMed]

36. Basaglia, G.; Pietrogrande, M.C. Optimization of a SPME/GC/MS Method for the Simultaneous Determination of Pharmaceuticals and Personal Care Products in Waters. Chromatographia 2012, 75, 361-370. [CrossRef]

37. Helenkar, A.; Sebok, A.; Zaray, G.; Molnar-Perl, I.; Vasanits-Zsigrai, A. The role of the acquisition methods in the analysis of the non-steroidal anti-inflammatory drugs in Danube River by gas chromatography-mass spectrometry. Talanta 2010, 82, 600-607. [CrossRef]

38. Lee, S.; Song, G.J.; Kannan, K.; Moon, H.B. Occurrence of PBDEs and other alternative brominated flame retardants in sludge from wastewater treatment plants in Korea. Sci. Total Environ. 2014, 470, 1422-1429. [CrossRef]

39. Molina-Fernandez, N.; Perez-Conde, C.; Rainieri, S.; Sanz-Landaluze, J. Method for quantifying NSAIDs and clofibric acid in aqueous samples, lumpfish (Cyclopterus lumpus) roe, and zebrafish (Danio rerio) eleutheroembryos and evaluation of their bioconcentration in zebrafish eleutheroembryos. Environ. Sci. Pollut. Res. 2016, 24, 10907-10918. [CrossRef] 
40. Vila, M.; Celeiro, M.; Lamas, J.P.; Garcia-Jares, C.; Dagnac, T.; Llompart, M. Simultaneous in-vial acetylation solid-phase microextraction followed by gas chromatography tandem mass spectrometry for the analysis of multiclass organic UV filters in water. J. Hazard. Mater. 2017, 323, 45-55. [CrossRef]

41. Wang, D.-G.; Zheng, Q.-D.; Wang, X.-P.; Du, J.; Tian, C.-G.; Wang, Z.; Ge, L.-K. Illicit drugs and their metabolites in 36 rivers that drain into the Bohai Sea and north Yellow Sea, north China. Environ. Sci. Pollut. Res. 2016, 23, 16495-16503. [CrossRef]

42. Weigel, S.; Kallenborn, R.; Hühnerfuss, H. Simultaneous solid-phase extraction of acidic, neutral and basic pharmaceuticals from aqueous samples at ambient (neutral) $\mathrm{pH}$ and their determination by gas chromatography-mass spectrometry. J. Chromatogr. A 2004, 1023, 183-195. [CrossRef] [PubMed]

43. Schymanski, E.L.; Jeon, J.; Gulde, R.; Fenner, K.; Ruff, M.; Singer, H.P.; Hollender, J. Identifying small molecules via high resolution mass spectrometry: Communicating confidence. Environ. Sci. Technol. 2014, 48, 2097-2098. [CrossRef] [PubMed]

(C) 2019 by the authors. Licensee MDPI, Basel, Switzerland. This article is an open access article distributed under the terms and conditions of the Creative Commons Attribution (CC BY) license (http://creativecommons.org/licenses/by/4.0/). 